\title{
DEVELOPMENT OF AFFINITY TECHNOLOGY FOR ISOLATING INDIVIDUAL HUMAN CHROMOSOMES BY THIRD STRAND BINDING
}

\author{
Final Technical Report
}

For Period May 1,1996 - January 31, 2001

Jacques R. Fresco, Principal Investigator

\author{
Department of Molecular Biology \\ Princeton University \\ Princeton, NJ 08544
}

June 2003

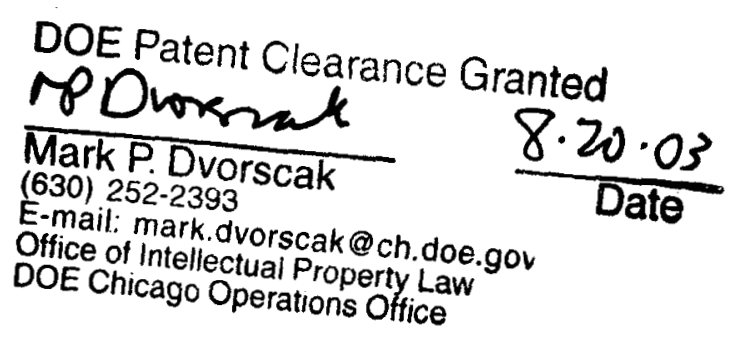

Prepared for

THE U.S. DEPARTMENT OF ENERGY

AWARD NO. DE-FG02-96ER62202 


\section{DISCLAIMER}

This report was prepared as an account of work sponsored by an agency of the United States Government. Neither the United States Government nor any agency Thereof, nor any of their employees, makes any warranty, express or implied, or assumes any legal liability or responsibility for the accuracy, completeness, or usefulness of any information, apparatus, product, or process disclosed, or represents that its use would not infringe privately owned rights. Reference herein to any specific commercial product, process, or service by trade name, trademark, manufacturer, or otherwise does not necessarily constitute or imply its endorsement, recommendation, or favoring by the United States Government or any agency thereof. The views and opinions of authors expressed herein do not necessarily state or reflect those of the United States Government or any agency thereof. 


\section{DISCLAIMER}

Portions of this document may be illegible in electronic image products. Images are produced from the best available original document. 
The specific goal of this project was to apply the concept of nucleic acid third strand binding for the purpose of exploring the possibility of isolating individual human chromosomes. Towards this end, a more general overall goal had to be developed, mainly to explore the possibility of utilizing nucleic acid third strands for the purpose of binding deoxyoligomers to specific target sequences within undenatured DNA in genomes by triple helix formation. Also, one had to find target sequences unique to each of the 23 pairs of human chromosomes.

To achieve these goals, it was first necessary to establish experimental conditions that keep erroneous binding to an absolute minimum. Once such conditions were developed, oligomer probes were utilized for many different purposes: 1) to "capture" large particles such as cosmids, plasmids, and whole chromosomes from complex mixtures by linking the probes to magnetic particles, which could be readily separated because of their magnetic properties; 2) to serve as cytogenetic probes of metaphase chromosomes; 3 ) to serve as cytogenetic probes of chromosomal DNA in formalin fixed, paraffin embedded tissue sections for diagnostic purposes; 4) to deliver reactive reagents to unique sites on chromosomes in vivo for the purpose of mutagenizing specific DNA base pairs. Of these goals, 1 was partially met, 2 and 4 fully met, while 3 has been met since DOE support was terminated, based largely on the foundation laid during the course of earlier NIH support and then the DOE-sponsored research.

In the case of the human chromosomes, a third strand binding target unique to the centromeres of each of the human chromosome pairs was found by data mining.

The research results of this project have been reported in four published papers, as follows.

Johnson, III, M.D., and Fresco, J.R. (1999) Third-strand In Situ hybridization (TISH) to non-denatured metaphase spreads and interphase nuclei. Chromosoma, 108:181-189. 
Broitman, S., Amosova, O., Dolinnaya, N., and Fresco, J.R. (1999) Repairing the Sickle Cell mutation. I. Specific covalent binding of a photoreactive third strand to the mutated base pair. J. Biol. Chem., 274:21763-21768.

Amosova, O., and Fresco, J.R. (1999) A search for base analogs to enhance third-strand binding to 'inverted' target base pairs of triplexes in the pyrimidine/parallel motif. Nucleic Acids Res. 27: 4632-4635.

Fabregat, I., Koch, K.S., Aoki, T., Atkinson, A.E., Dang, H., Amosova, O., Fresco, J.R., Schildkraut, C.L., and Leffert, H.L. (2001) Functional pleiotropy of an intramolecular triplex-forming fragment from the 3'UTR of the rat Pigr gene. Physiol Genomics, 5:5365.

In addition 2-3 other publications remain to be completed. The first of the published papers, that by Johnson and Fresco, is undoubtedly the most important from the point of view of the major research goal. This paper describes in detail the rationale and a methodology for binding third strand probes to native DNA in the $\alpha$-satellite region of human chromosome 17. (Subsequently, such a probe was analyzed for the Xchromosome.) It is apparent from the specificity of the 16-nucleotide probe for the target sequence in chromosome 17 that third strand binding affords the necessary specificity to select out a single chromosome. The covalent attachment of that probe to a magnetic bead was found in preliminary experiments to afford relative specificity for those two chromosomes among the 24 pairs in a human cell, but that effort was not pursued to completion due to the extreme effort required both to bring the contents of the JohnsonFresco paper to completion and the additional experimental work devoted to other efforts to demonstrate the uniqueness of nucleic acid third strand binding under conditions that required major innovation and analysis. It was also shown that the specificity of the probe under the binding conditions was sensitive to a single base pair difference.

The so called TISH (third strand in situ hybridization) technology described in the Johnson-Fresco paper has drawn considerable attention, is being applied by others for the 
fluorescent labeling of whole chromosomes and also for the development of various biomedically valuable diagnostic probes. For the latter, conditions have had to be substantially modified for use with formalin-fixed, paraffin embedded tissue sections.

A second derivative result of the research is found in the paper by Amosova and Fresco. There the goal was to attempt to extend third strand binding to nonhomopurine would not be limited to the $1-2 \%$, for example, of the human genome; the other $98 \%$ do not constitute stereochemically compatible target sequences for third strand binding. Partial success towards this goal was achieved by finding a number of base analogs that with greater or lesser affinity can be used to bind to "inverted" target base pairs that violate the requirement of all-purine•all-pyrimidine base pairs; in other words a pyrimidine•purine pair within a run of purine-pyrimidine pairs. In fact, the findings from this study were exploited in the next investigation initiated under this research grant, i.e., the paper by Broitman, Amosova, Dolinnaya, and Fresco.

That paper described the initial efforts to develop a third strand binding probe to deliver the photo-reactive reagent psoralen to the specific site in the human $\beta$-globin gene, which, when it undergoes a transversion mutation causes Sickle Cell Anemia. The effort in this case had to be directed to developing a third strand probe to deliver the psoralen reagent to a section of the gene with a sequence that contains many "inverted" base pairs, and to deliver it with such specificity that the probe would bind nowhere else in the human genome. This project then, was a particularly severe test of the specificity that could be achieved with third strand binding, all the more so because it is hampered by the presence of many inverted base pairs. This goal was met utilizing, in part, two of the base analogs described in the Amosova and Fresco paper, 5-propynyl $U$ and 5-methyl $C$. This investigation had other values as well, which have been followed up more recently to develop a general method for gene repair in cases of human diseases caused by different point mutations. 
The last paper completed in the area of third strand binding specificity involved an analysis of a case of intramolecular triple helix formation in a human gene that plays a regulatory role.

While the actual goal for utilizing third strand binding sequences to isolate intact human chromosomes was not fully met in the course of this project, the methodology developed does enable fluorescent labeling of such chromosomes for flow sorting. More important, with more intense effort, we believe that the stage is set for achieving the original goal if it is still needed, based in very large measure on the research results obtained in this study. In any event, the method does work for plasmids, cosmids and other large double stranded nucleic acid helices; and the other derivative knowledge has proved to be valuable for its own sake and in various other applications.

Additional reports of some of the researches initiated under the DOE support, but followed by further research from other sources can be expected, in which case they will be made known to DOE and suitably acknowledged in due course. 